\title{
BMJ Open Effective psychological and psychosocial approaches to reduce repetition of self-harm: a systematic review, meta-analysis and meta-regression
}

\author{
Sarah E Hetrick, ${ }^{1,2}$ Jo Robinson, ${ }^{1,2}$ Matthew J Spittal, ${ }^{3}$ Greg Carter ${ }^{4}$
}

To cite: Hetrick SE, Robinson J, Spittal MJ, et al. Effective psychological and psychosocial approaches to reduce repetition of selfharm: a systematic review, meta-analysis and meta-regression. BMJ Open 2016;6:e011024. doi:10.1136/bmjopen-2016011024

- Prepublication history and additional material is available. To view please visit the journal (http://dx.doi.org/ 10.1136/bmjopen-2016011024)

Received 5 January 2016 Revised 11 August 2016 Accepted 23 August 2016

CrossMark

For numbered affiliations see end of article.

Correspondence to Dr Sarah E Hetrick; shetrick@unimelb.edu.au

\section{ABSTRACT}

Objective: To examine the efficacy of psychological and psychosocial interventions for reductions in repeated self-harm.

Design: We conducted a systematic review, metaanalysis and meta-regression to examine the efficacy of psychological and psychosocial interventions to reduce repeat self-harm in adults. We included a sensitivity analysis of studies with a low risk of bias for the metaanalysis. For the meta-regression, we examined whether the type, intensity (primary analyses) and other components of intervention or methodology (secondary analyses) modified the overall intervention effect.

Data sources: A comprehensive search of MEDLINE, Psyclnfo and EMBASE (from 1999 to June 2016) was performed.

Eligibility criteria for selecting studies:

Randomised controlled trials of psychological and psychosocial interventions for adult self-harm patients.

Results: Forty-five trials were included with data available from 36 (7354 participants) for the primary analysis. Meta-analysis showed a significant benefit of all psychological and psychosocial interventions combined (risk ratio $0.84 ; 95 \% \mathrm{Cl} 0.74$ to 0.96 ; number needed to treat=33); however, sensitivity analyses showed that this benefit was non-significant when restricted to a limited number of high-quality studies. Meta-regression showed that the type of intervention did not modify the treatment effects.

Conclusions: Consideration of a psychological or psychosocial intervention over and above treatment as usual is worthwhile; with the public health benefits of ensuring that this practice is widely adopted potentially worth the investment. However, the specific type and nature of the intervention that should be delivered is not yet clear. Cognitive-behavioural therapy or interventions with an interpersonal focus and targeted on the precipitants to self-harm may be the best candidates on the current evidence. Further research is required.

\section{INTRODUCTION}

Clinically treated non-fatal self-harm (we use the term self-harm henceforth) is common.

\section{Strengths and limitations of this study}

- We used robust systematic review methodology, including analysis of meaningful secondary outcomes, and sensitivity analysis to assess the impact of risk of bias on the results.

- Our search was thorough and has identified 45 relevant randomised controlled trials; this is the largest number of trials identified in a systematic review of this type.

- The risk of bias in various domains was rated as high, and sensitivity analyses when restricted to a limited number of high-quality studies showed that this benefit was non-significant.

- There were few trials of some types of interventions undertaken, limiting the power of the analysis to show an effect in meta-regression.

- Results of the meta-regression are observational in nature and cannot infer causality; as such, they are considered to be hypothesis generating rather than providing robust conclusions.

A landmark systematic review of 90 observational studies from Western countries estimated a 1-year repetition rate of self-harm of $16 \%$, while the suicide rate was $2 \%$ after 1 year and $7 \%$ after 9 years. ${ }^{1}$ A more recent review of 177 studies from Western and non-Western countries indicated little change in these estimates, with reported repetition of self-harm of $16.3 \%$ after 1 year, while the suicide mortality rate was $1.6 \%$ after 1 year and $3.9 \%$ after 5 years. ${ }^{2}$ Self-harm is problematic in terms of adverse outcomes such as repetition of self-harm, suicide and all-cause mortality; mental health morbidity, quality of life and physical, psychological and social functioning. It is also costly in terms of immediate and ongoing treatment. $^{12}$

Despite this, there is relatively limited evidence about the efficacy of psychological 
and psychosocial interventions to prevent the repetition of self-harm, ${ }^{3-6}$ particularly because of the limited number of trials, the small sample size of many trials and the diversity of interventions tested. Large-scale randomised controlled trials (RCTs) are considered to be difficult to conduct due to ethical concerns regarding withholding potentially efficacious interventions (in the control group) from people at risk. ${ }^{7} 8$ In addition, studies are frequently underpowered, ${ }^{8-10}$ lack a standardised definition of self-harm ${ }^{11} 12$ and have marked differences in assessment tools and reporting of outcomes, which leads to difficulties in pooling data.

A seminal Cochrane review of 23 RCTs published in $1999^{13}$ examining the efficacy of psychological and pharmacological interventions for reducing repeat selfharm in any clinical population included an analysis of risk of bias; and (where possible) meta-analyses of therapies and medications classified by type of therapy and type of medication. The authors concluded that there was potential benefit of problem-solving therapy (five studies), the provision of an emergency access card (two studies) and, based on one study each, of depot flupenthixol treatment and dialectical behavioural therapy (DBT) in reducing repetition of self-harm. Overall the conclusions were that there remained considerable uncertainty with regard to the efficacy of any intervention for repeat self harm. The recently published Cochrane reviews that update this evidence show (1) that few pharmacological interventions have any statistically significant effect on reducing repetition of selfharm, except flupenthixol, for which there is one lowquality trial to date $\mathrm{e}^{14}$ and (2) that there is some evidence that cognitive-behavioural therapy (CBT) (and not problem-solving therapy) can reduce repetition of self-harm in unselected populations, but again highlight the poor quality of the evidence base. ${ }^{15}$

In addition to these Cochrane reviews, a number of trials have been published and several systematic reviews produced that aim to highlight what interventions are most efficacious. ${ }^{16-25}$ Reviews have been based on narrative summaries of indirect comparisons (using data from separate trials, in contrast to direct comparison in head-to-head RCTs) and endorsed CBT, ${ }^{3} \quad 20 \quad 23 \quad 26$ DBT $^{19} 2326$ and problem-solving therapy; ${ }^{5}{ }^{26}$ one has endorsed psychodynamic therapy. ${ }^{23}$ However, they have been unable to provide definitive guidance about whether the type of intervention delivered, individual components of interventions or components of study methodology modify the overall treatment. This is because they have either only examined the effects of specific types of interventions, or the efficacy of interventions in specific clinical populations/diagnostic groups, or have been limited by non-systematic search strategies, absent quality appraisal techniques, a lack of quantitative synthesis and techniques to appropriately investigate such modifying effects.

The National Institute for Health and Care Excellence (NICE) recommends "Consider offering 3 to 12 sessions of a psychological intervention that is specifically structured for people who self-harm, with the aim of reducing self-harm" (ref. 27, p. 10). The guidelines include cautious recommendations about the type of therapy to offer, 'the intervention should be tailored to individual need, and could include cognitive-behavioural, psychodynamic or problem-solving elements'. This cautious approach is appropriate given that, to date, the evidence for which types of psychotherapy are more effective has been derived from narrative summaries of indirect comparisons.

A more sophisticated quantitative analysis is therefore needed to robustly explore this question. One method for doing this is meta-regression. ${ }^{28}$ This approach has been useful in other populations by examining the capacity for the type of psychological interventions to modify outcomes. For example, a meta-regression of trials of Collaborative Care interventions for depression in primary care found that the particular type of Collaborative Care provided modified the intervention effect. ${ }^{29}$ A meta-regression of psychological interventions in primary care also showed that the type of psychological intervention did not modify the overall effects of intervention on depression and anxiety symptoms compared with treatment as usual (TAU). ${ }^{30}$

It is currently unclear whether psychological interventions are beneficial overall and there is little evidencebased guidance to clinicians as to the specific type of psychological or psychosocial intervention to offer individuals in order to prevent repetition of self-harm. We planned to identify all relevant studies in order to calculate pooled estimates of efficacy overall and for interventions categorised by type, and to examine possible modifiers of treatment effect.

\section{METHODS \\ Aims}

The aims of this systematic review are to (1) update the evidence base by evaluating the efficacy of psychological and psychosocial interventions to reduce repeat selfharm, (primary outcome) and to reduce suicidal ideation, depression and hopelessness (secondary outcomes) using meta-analysis; and (2) examine whether the type, intensity or other specific components of the interventions, or study methodology, modify the pooled intervention effect using meta-regression.

The conduct of the review is based on Cochrane systematic review methodology ${ }^{28}$ and conforms to the PRISMA checklist ${ }^{31}$ with regard to the reporting of the review (see online supplementary table S1). There is no registered protocol for this review.

\section{Eligibility criteria for selecting studies}

Only RCTs were eligible for inclusion as these are considered to provide the strongest measure of whether an intervention has an effect because this design minimises bias. ${ }^{32}$ These RCTs were of psychological or psychosocial 
interventions for adults (>18) who had recently presented to clinical settings, including but not limited to emergency departments and hospitals, having engaged in self-harm, which for the purposes of this review included behaviours variously referred to by trial authors as self-harm, deliberate self-harm, self-poisoning, deliberate self-poisoning, parasuicide or suicide attempt. We would have also accepted any studies using other alternate terms, for example, overdose or suicidal gesture. We excluded RCTs where it was clear that participants were recruited on the basis of having deliberately tried to injure themselves without suicidal intent (often referred to as non-suicidal self-injury, which is generally considered to be a different, although overlapping phenomenon). ${ }^{33}$ We did not impose any language restriction, for example, English language.

Interventions had to be primarily delivered directly to patients, as opposed to being aimed at the clinicians treating them. Trials of brief contact interventions, such as telephone contacts; crisis cards, or postcards; pharmacological interventions; and trials undertaken in subpopulations selected on the basis of borderline personality disorder (BPD), depressive disorder or psychosis were excluded with the aim of ensuring a homogeneous group of trials, given that one of our primary aims was to explore the modifying effects of the type and nature of psychological and psychosocial interventions delivered.

We included any comparator including TAU; enhanced TAU (TAU+), defined as seeking to ensure engagement in TAU; alternative controlled intervention; no treatment; and waitlist control.

The primary binary outcome was any repeat episode of self-harm (which included behaviours referred to by trial authors as deliberate self-harm, self-harm, selfpoisoning, deliberate self-poisoning, parasuicide and suicide attempt). We did not set any limit on time to repetition and when data for more than one follow-up was provided, we selected the longest follow-up point. Secondary continuous outcomes included self-rated severity of suicidal ideation, depression and hopelessness measured on standardised scales. These secondary outcomes have been shown to be associated with self-harm ${ }^{34-36}$ and were considered to be important secondary outcomes in their own right.

\section{Search strategy and key words}

We first searched the reference list of the seminal Cochrane review on treatments for self-harm originally published in $1999^{5}$ and recently updated. ${ }^{15}$ To find articles published since the original publication of this review, we undertook electronic searches of MEDLINE, PsycInfo and EMBASE (from 1999 to June 2016) using a combination of terms relevant to self-harm and terms designed to retrieve controlled trials (see online supplementary table S2 for MEDLINE search strategy). We also examined the reference lists of included trials and relevant reviews, and contacted experts in the field.
Study selection, data extraction and risk of bias assessment

Two authors (SEH and JR) independently selected trials and extracted data on characteristics of the trial (see online supplementary table S3) and on the nature of the psychological and psychosocial interventions (see online supplementary table S4), and outcome data using previously piloted data extraction forms. Discrepancies were resolved by a third author (GC).

Risk of bias was assessed independently by two authors (SEH and JR) based on Cochrane Collaboration methodology. ${ }^{37}$ Trials were assessed as being of low risk, unclear risk or high risk of bias in four domains: (1) random sequence generation; (2) allocation concealment; (3) blinding of outcome assessors; (4) extent, and management, of incomplete outcome data, in particular whether an intent-to-treat (ITT) analysis was conducted (see table 1).

For the final domain (5), trials were judged as being of a low risk of bias if they had $<15 \%$ missing data, as unclear risk if they had $>15 \%$ missing data and conducted ITT analysis, and as high risk of bias if there was over $15 \%$ missing data and no ITT analysis or if it was not clear whether ITT analysis was conducted.

\section{Statistical analyses}

For all analyses, we used the Comprehensive Meta-Analysis (CMA) software (Comprehensive Meta-analysis [program]. 3 version. Englewood, NJ: Biostat, 2014).

\section{Meta-analysis}

For the primary outcome (any repetition of self-harm), we pooled data to calculate a risk ratio (RR) and, when this estimate was significantly different from 1 , the number needed to treat (NNT). The secondary outcomes were all continuous outcomes. We converted suicidal ideation and depression scores to the standardised mean difference (SMD). Since hopelessness was uniformly measured using the Beck Hopelessness Scale, we used the mean difference. We pooled estimates of treatment effect using a random-effects model with 95\% CIs.

\section{Additional analyses}

Meta-analysis sensitivity analyses

We undertook a sensitivity analysis to assess the impact of trials judged to be either at a high or unclear risk of bias, for the domains of allocation concealment and outcome assessor blinding, given that these have been shown to have the largest impact on effect estimates. ${ }^{83}$

\section{Meta-regression}

Owing to the restricted number of trials, we entered only one covariate in a series of random-effects regression models using the $\log \mathrm{RR}$ and its corresponding 95\% CIs to examine the type, intensity and components of the interventions and the study methodology, which we expected to have the strongest influence on repeated self-harm using a priori chosen independent variables: 


\begin{tabular}{|c|c|c|c|c|c|c|}
\hline Reference & $\begin{array}{l}\text { Random } \\
\text { sequence } \\
\text { generation }\end{array}$ & $\begin{array}{l}\text { Allocation } \\
\text { concealment }\end{array}$ & $\begin{array}{l}\text { hospital records (or } \\
\text { some other objectively } \\
\text { recorded method) }\end{array}$ & $\begin{array}{l}\text { self harm } \\
\text { outcome) } \\
\text { blinded? }\end{array}$ & $\begin{array}{l}\text { rate }>15 \% \\
\text { for self } \\
\text { harm data }\end{array}$ & $\begin{array}{l}\text { ITT } \\
\text { analysis } \\
\text { performed }\end{array}$ \\
\hline \multicolumn{7}{|l|}{ Problem focused } \\
\hline Bannan $^{38}$ & Coin toss & $\mathrm{N}$ & Not described & NA & $\mathrm{N}$ & $\mathrm{N}$ \\
\hline Gibbons et $a \beta^{\beta 9}$ & Not described & Not described & Hospital records & $Y$ & Unclear & $\begin{array}{l}\text { Not } \\
\text { described }\end{array}$ \\
\hline Hatcher et $a f^{40}$ & $\begin{array}{l}\text { Computer } \\
\text { generated }\end{array}$ & $\mathrm{Y}$ & Both & Y & $\mathrm{N}$ & $\mathrm{Y}$ \\
\hline Hawton et $a f^{11}$ & Not described & Not described & Both & $\mathrm{Y}$ & $\mathrm{Y}$ & $\mathrm{N}$ \\
\hline Husain et $a f^{42}$ & $\begin{array}{l}\text { Computer } \\
\text { generated }\end{array}$ & $\mathrm{Y}$ & Interview & Y & $\mathrm{N}$ & $\begin{array}{l}\text { Not } \\
\text { described }\end{array}$ \\
\hline McAuliffe et $a{ }^{43}$ & $\begin{array}{l}\text { Computer } \\
\text { generated }\end{array}$ & $\mathrm{Y}$ & Interview & Not described & $Y$ & $\begin{array}{l}\text { Not } \\
\text { described }\end{array}$ \\
\hline McLeavey et $a /^{44}$ & Not described & Not described & $\begin{array}{l}\text { GP questionnaire and } \\
\text { hospital records }\end{array}$ & $Y$ & Unclear & $\begin{array}{l}\text { Not } \\
\text { described }\end{array}$ \\
\hline $\begin{array}{l}\text { Patsiokas and } \\
\text { Clum }^{45}\end{array}$ & Not described & Not described & $\begin{array}{l}\text { Self harm outcomes not } \\
\text { collected }\end{array}$ & NA & Unclear & $\begin{array}{l}\text { Not } \\
\text { described }\end{array}$ \\
\hline Stewart et $a f^{46}$ & Drawing of lots & Not described & Hospital records & $\mathrm{N}$ & $\mathrm{Y}$ & $\mathrm{N}$ \\
\hline Salkovskis et $a \mathrm{f}^{47}$ & Not described & Not described & Hospital records & Not described & Unclear & $\begin{array}{l}\text { Not } \\
\text { described }\end{array}$ \\
\hline \multicolumn{7}{|l|}{$C B T$} \\
\hline Brown et a $f^{48}$ & $\begin{array}{l}\text { Computer } \\
\text { generated }\end{array}$ & Not described & Interview & $\mathrm{N}$ & Y & Y \\
\hline Evans et $a f^{49}$ & Not described & $\mathrm{Y}$ & Both & $\mathrm{Y}$ & $\mathrm{N}$ & $\mathrm{N}$ \\
\hline $\begin{array}{l}\text { Liberman and } \\
\text { Eckman }^{50}\end{array}$ & Not described & Not described & Interview & Not described & $\mathrm{N}$ & $\begin{array}{l}\text { Not } \\
\text { described }\end{array}$ \\
\hline Morley et $a^{P^{1}}$ & Not described & Not described & Interview & $\mathrm{Y}$ & $\mathrm{Y}$ & $\mathrm{Y}$ \\
\hline Rudd et $a^{F^{2}}$ & $\begin{array}{l}\text { Computer } \\
\text { generated }\end{array}$ & Not described & Interview & Y & Y & Y \\
\hline Slee et $a^{\Gamma^{3}}$ & $\begin{array}{l}\text { Computer } \\
\text { generated }\end{array}$ & $\mathrm{Y}$ & Interview & $\mathrm{N}$ & $\mathrm{N}$ & $\begin{array}{l}\text { Not } \\
\text { described }\end{array}$ \\
\hline Tyrer et $a^{54}$ & $\begin{array}{l}\text { Computer } \\
\text { generated }\end{array}$ & $\mathrm{Y}$ & Both & Not described & $\mathrm{N}$ & $\begin{array}{l}\text { Not } \\
\text { described }\end{array}$ \\
\hline \multicolumn{7}{|l|}{ Psychodynamic } \\
\hline Guthrie et $a^{55}$ & Not described & Not described & Both & $\mathrm{Y}$ & $\mathrm{Y}$ & $\mathrm{Y}$ \\
\hline \multicolumn{7}{|c|}{ Complex interventions with outreach } \\
\hline Allard et $a^{56}$ & Not described & $\mathrm{Y}$ & Both & Not described & $\mathrm{Y}$ & Y \\
\hline Clarke et $a^{77}$ & $\begin{array}{l}\text { Random } \\
\text { numbered lists }\end{array}$ & $\mathrm{Y}$ & Hospital records & Not described & $\mathrm{N}$ & $\begin{array}{l}\text { Not } \\
\text { described }\end{array}$ \\
\hline Comtois et $a^{58}$ & $\begin{array}{l}\text { Computer } \\
\text { generated }\end{array}$ & $\mathrm{N}$ & Interview & Y & Y & $\mathrm{Y}$ \\
\hline Hatcher et $a^{59}$ & $\begin{array}{l}\text { Computer } \\
\text { generated }\end{array}$ & $Y$ & Hospital records & Y & $\mathrm{N}$ & Y \\
\hline Hatcher et $a^{f 0}$ & $\begin{array}{l}\text { Computer } \\
\text { generated }\end{array}$ & $Y$ & Hospital records & $Y$ & $Y$ & $Y$ \\
\hline Hawton et $a{ }^{61}$ & Not described & Not described & Both & $Y$ & $\mathrm{~N}$ & $\begin{array}{l}\text { Not } \\
\text { described }\end{array}$ \\
\hline Hvid et $a \rho^{2}$ & Not described & $\mathrm{Y}$ & Hospital records & $\mathrm{Y}$ & $\mathrm{N}$ & $\mathrm{Y}$ \\
\hline Kawanishi et $a^{{ }^{3}}$ & $\begin{array}{l}\text { Computer } \\
\text { generated }\end{array}$ & $Y$ & Interview & Y & $Y$ & Y \\
\hline $\begin{array}{l}\text { Marasinghe } \\
\text { et } a^{\beta^{4}}\end{array}$ & Not described & Not described & Not described & $\mathrm{Y}$ & Unclear & Y \\
\hline Morthorst et a ${ }^{65}$ & Not described & $Y$ & Hospital records & $Y$ & $\mathrm{~N}$ & $Y$ \\
\hline $\begin{array}{l}\text { Litman and } \\
\text { Wold }\end{array}$ & $\begin{array}{l}\text { Table of } \\
\text { random } \\
\text { numbers }\end{array}$ & Not described & Not described & Not described & Unclear & $\begin{array}{l}\text { Not } \\
\text { described }\end{array}$ \\
\hline
\end{tabular}

Was self harm repetition ascertained via interview or hospital records (or

\section{Out}

Outcome assessor (for Drop-out rate $>15 \%$ for self analysis performed

Reference

Coin toss
Not describ

$\mathrm{N}$

ot described

Both

Computer

Both

Interview

$Y$

NA

$\mathrm{N}$ 


\begin{tabular}{|c|c|c|c|c|c|c|}
\hline Reference & $\begin{array}{l}\text { Random } \\
\text { sequence } \\
\text { generation }\end{array}$ & $\begin{array}{l}\text { Allocation } \\
\text { concealment }\end{array}$ & $\begin{array}{l}\text { hospital records (or } \\
\text { some other objectively } \\
\text { recorded method) }\end{array}$ & $\begin{array}{l}\text { self harm } \\
\text { outcome) } \\
\text { blinded? }\end{array}$ & $\begin{array}{l}\text { rate }>15 \% \\
\text { for self } \\
\text { harm data }\end{array}$ & $\begin{array}{l}\text { ITT } \\
\text { analysis } \\
\text { performed }\end{array}$ \\
\hline $\begin{array}{l}\text { Van der Sande } \\
\text { et } a f^{67}\end{array}$ & $\begin{array}{l}\text { Computer } \\
\text { generated }\end{array}$ & $\mathrm{Y}$ & Hospital records & $\mathrm{N}$ & $\mathrm{Y}$ & $\mathrm{Y}$ \\
\hline $\begin{array}{l}\text { Van Heeringen } \\
\text { et } a \rho^{88}\end{array}$ & Not described & Not described & $\begin{array}{l}\text { Interview including GP } \\
\text { interview and check of } \\
\text { death records }\end{array}$ & Not described & $\mathrm{Y}$ & $\begin{array}{l}\text { Not } \\
\text { described }\end{array}$ \\
\hline Wei et $a^{69}$ & $\begin{array}{l}\text { Computer } \\
\text { generated }\end{array}$ & Not described & Interview & Not described & Y & Y \\
\hline Welu ${ }^{70}$ & $\begin{array}{l}\text { Table of } \\
\text { random } \\
\text { numbers }\end{array}$ & Not described & Both & Not described & Unclear & $\begin{array}{l}\text { Not } \\
\text { described }\end{array}$ \\
\hline \multicolumn{7}{|c|}{ Other-psychological } \\
\hline Dubois et $a l^{71}$ & Not described & Not described & Interview & Not described & $\mathrm{N}$ & $\begin{array}{l}\text { Not } \\
\text { described }\end{array}$ \\
\hline $\begin{array}{l}\text { Gysin-Maillart } \\
\text { et } a l^{22}\end{array}$ & Shuffling & Y & $\begin{array}{l}\text { Self-report } \\
\text { questionnaire and } \\
\text { hospital records and } \\
\text { contact with GPs and } \\
\text { therapists }\end{array}$ & $\mathrm{N}$ & $\mathrm{N}$ & Y \\
\hline Tapolaa et $a l^{73}$ & Not described & Not described & Interview & $\mathrm{N}$ & $\mathrm{N}$ & $\begin{array}{l}\text { Not } \\
\text { described }\end{array}$ \\
\hline Torhorst et $a l^{74}$ & Not described & Not described & Interview & Not described & $\mathrm{N}$ & $\begin{array}{l}\text { Not } \\
\text { described }\end{array}$ \\
\hline Torhorst et $a l^{75}$ & Not described & Not described & Not described & Not described & Y & $\begin{array}{l}\text { Not } \\
\text { described }\end{array}$ \\
\hline \multicolumn{7}{|l|}{ Other-psychosocial } \\
\hline Armitage et $a l^{76}$ & $\begin{array}{l}\text { Computer } \\
\text { generated }\end{array}$ & $\mathrm{N}$ & $\begin{array}{l}\text { Self-report } \\
\text { questionnaire }\end{array}$ & $\mathrm{N}$ & Y & Y \\
\hline Crawford et $a l^{77}$ & Not described & Y & Both & $\mathrm{Y}$ & $\mathrm{N}$ & $\begin{array}{l}\text { Not } \\
\text { described }\end{array}$ \\
\hline Grimholt et $a l^{78}$ & $\begin{array}{l}\text { Computer } \\
\text { generated }\end{array}$ & Y & $\begin{array}{l}\text { Self-report } \\
\text { questionnaire and } \\
\text { hospital records }\end{array}$ & $\begin{array}{l}\text { Blind in } 70 \% \\
\text { of cases }\end{array}$ & Y & $\mathrm{Y}$ \\
\hline Mouaffak et $a l^{79}$ & Not described & $\mathrm{Y}$ & Both & Not described & $\mathrm{N}$ & $\mathrm{Y}$ \\
\hline O'Connor et $a^{\beta 0}$ & Not described & Not described & $\begin{array}{l}\text { Self harm outcomes } \\
\text { not collected }\end{array}$ & NA & $\mathrm{Y}$ & $\mathrm{N}$ \\
\hline Wang et $a^{\beta 1}$ & Not described & Y & $\begin{array}{l}\text { National suicide } \\
\text { prevention reporting } \\
\text { sheets }\end{array}$ & Not described & $\mathrm{N}$ & $\mathrm{N}$ \\
\hline $\begin{array}{l}\text { Waterhouse and } \\
\text { Platt }^{82}\end{array}$ & Not described & $\mathrm{Y}$ & $\begin{array}{l}\text { Interview and } \\
\text { questionnaire with GP, } \\
\text { and review of case } \\
\text { records }\end{array}$ & $\mathrm{N}$ & $\mathrm{Y}$ & $\begin{array}{l}\text { Not } \\
\text { described }\end{array}$ \\
\hline
\end{tabular}

1. Type of intervention, classified into six categories: problem-focused (including problem-solving therapy) interventions, CBT, complex intervention (that included various combinations of psychotherapy or case management with periods of inpatient care, assertive approaches to ensuring engagement such as flexibility with regard to where patients were seen, phone calls and reminders; and crisis management), and psychodynamic interpersonal, other-psychological and other-psychosocial therapy.

2. Intensity, scored as the total planned hours of therapy and/or contact.

3. Components of intervention: home visits; betweensession contact emphasising motivation to attend; continuity of care between the acute hospital and outpatient setting; clinician access for crisis management; and the presence of an inpatient component. 
4. Type of comparator condition: TAU, TAU+, alternative controlled intervention, no intervention or waitlist.

5. Study population defined by nature of the suicidal behaviour: self-harm (including where original studies used any synonyms or alternate definitions for selfharm, eg, deliberate self-harm or parasuicide), selfpoisoning (including where original studies used the synonym deliberate self-poisoning) or suicide attempt.

6. Total sample size analysed.

\section{Heterogeneity}

Heterogeneity was assessed as per Cochrane methodology $^{28}\left(\mathrm{I}^{2}\right.$ values of $0-40 \%$ : might not be important; 30-60\%: moderate heterogeneity; 50-90\%: substantial heterogeneity; 75-100\%: considerable heterogeneity), taking into account (1) magnitude and direction of effects and (2) strength of evidence for heterogeneity (eg, $\mathrm{p}$ value from the $\chi^{2}$ test, or a CI for $\mathrm{I}^{2}$ ).

\section{Assessment of reporting bias}

Reporting bias (systematic differences between reported and unreported findings) was assessed by entering data into a funnel plot.

\section{RESULTS}

\section{Study selection}

Ancestry searching of the existing Cochrane review ${ }^{5}$ identified 15 relevant trials. After removing duplicates, 4348 articles were retrieved from the search of electronic databases. Inspection of titles and abstracts resulted in the exclusion of 4218 articles. There were eight reviews for ancestry searching, including the newly published Cochrane review, 614232426 84-86 from which seven relevant trials were identified. After full-text inspection of 137 articles, 92 were excluded. We included 30 new trials in addition to the 15 trials from the original Cochrane review. Of 45 included trials, 36 published usable data (based on 7354 participants) for meta-analysis of the primary outcome (see figure 1) and 37 provided data for at least one of the secondary outcomes.

\section{Study characteristics}

A description of trial characteristics is shown in online supplementary table S3. The majority of trials that provided data for the primary outcome $(\mathrm{n}=19){ }^{41} 42 \quad 48 \quad 52 \quad 55 \quad 56 \quad 60-62 \quad 65 \quad 6769-72 \quad 7475 \quad 77 \quad 78 \quad 87$ were medium (80-280 participants), eight were small $(<80$ participants) ${ }^{38} \quad 44 \quad 4749 \quad 5058 \quad 8182$ and nine were large (>280 participants). ${ }^{394043545759636879}$ Of the remaining trials that did not contribute data to the primary outcome, five trials were small, ${ }^{45} 46647380$ three were medium $;{ }^{515376}$ and one was large. ${ }^{66}$

\section{Types of participants}

Twenty-one trials included participants on the basis of a recent episode of self-harm (variously referred to in the original studies as deliberate self-harm, self-harm, selfpoisoning, deliberate self-poisoning or parasuicide by the trial authors; see online supplementary table S3) $4042434953-555759-6173 \quad 76-7882$ and 21 trials on the basis of what was specifically referred to as recent hospital-treated suicide attempt. ${ }^{45-48} 50515658$ 63-65 67-72 $747579-81$ One trial included participants on the basis of suicidal ideation with intent to die and/or suicide attempt ${ }^{52}$ one trial included participants who had a recent episode of hospital or clinic-treated self-harm or suicide attempt. ${ }^{62}$ Inclusion criteria were unclear in one trial, but it is unlikely they were all hospital-treated ${ }^{66}$ (see online supplementary table S3).

\section{Types of interventions}

Forty-two trials were a simple comparison between an intervention and control arm. Seven tested CBT, and 15 tested complex interventions. The complex interventions with outreach included combinations of therapy or case management, plus various additional components (see online supplementary tableS4 for details). Eight trials tested a problem-focused therapy and one tested psychodynamic interpersonal psychotherapy. Twelve trials tested an intervention we classified as 'other'. Five of these were classed as 'other-psychological' and include one trial that tested psychotherapy that included elements of acceptance and commitment therapy plus solution-focused brief therapy compared with TAU $;{ }^{73}$ a trial of unspecified psychological intervention compared with TAU; ${ }^{71}$ a trial of ASSIP, which consists of an unspecified psychological intervention and letters compared with TAU; ${ }^{72}$ and two trials of an unspecified psychological intervention that was delivered either by the same or different therapy; ${ }^{74}$ or over 3 months compared with over 12 months. ${ }^{75}$ The remaining seven trials were classed as 'other-psychosocial' and tested: sending an appointment card; ${ }^{77}$ self-help development of a plan not to self-harm; ${ }^{76}$ six structured general practice (GP) consultations; ${ }^{78} 87$ a programme called OSTA where a series of phone calls were made to encourage adherence to interventions; ${ }^{79}$ development of a crisis response plan based on identification of factors underlying self-harm ${ }^{80}$ (see online supplementary table S4).

Three trials had three arms that included two active intervention arms and one control group. One compared cognitive restructuring, problem-solving and a nondirective supportive condition. ${ }^{45}$ The second compared a complex intervention, $\mathrm{CBT}$ and a no-intervention control. ${ }^{69}$ However, few participants randomised to CBT $(5 / 82)$ received CBT, so we have only included two trial arms: the complex intervention arm and the no-intervention arm and omitted the CBT arm from analyses. $^{69}$ The third compared CBT, problem-solving therapy and TAU. ${ }^{46}$

\section{Control conditions}

Thirty trials used TAU, and six used TAU+ as the comparator. ${ }^{384348545863}$ Seven trials used an alternative 
Figure 1 Flow chart of study selection. BPD, borderline personality disorder; NSSI, non-suicidal self-injury; RCT, randomised controlled trial.

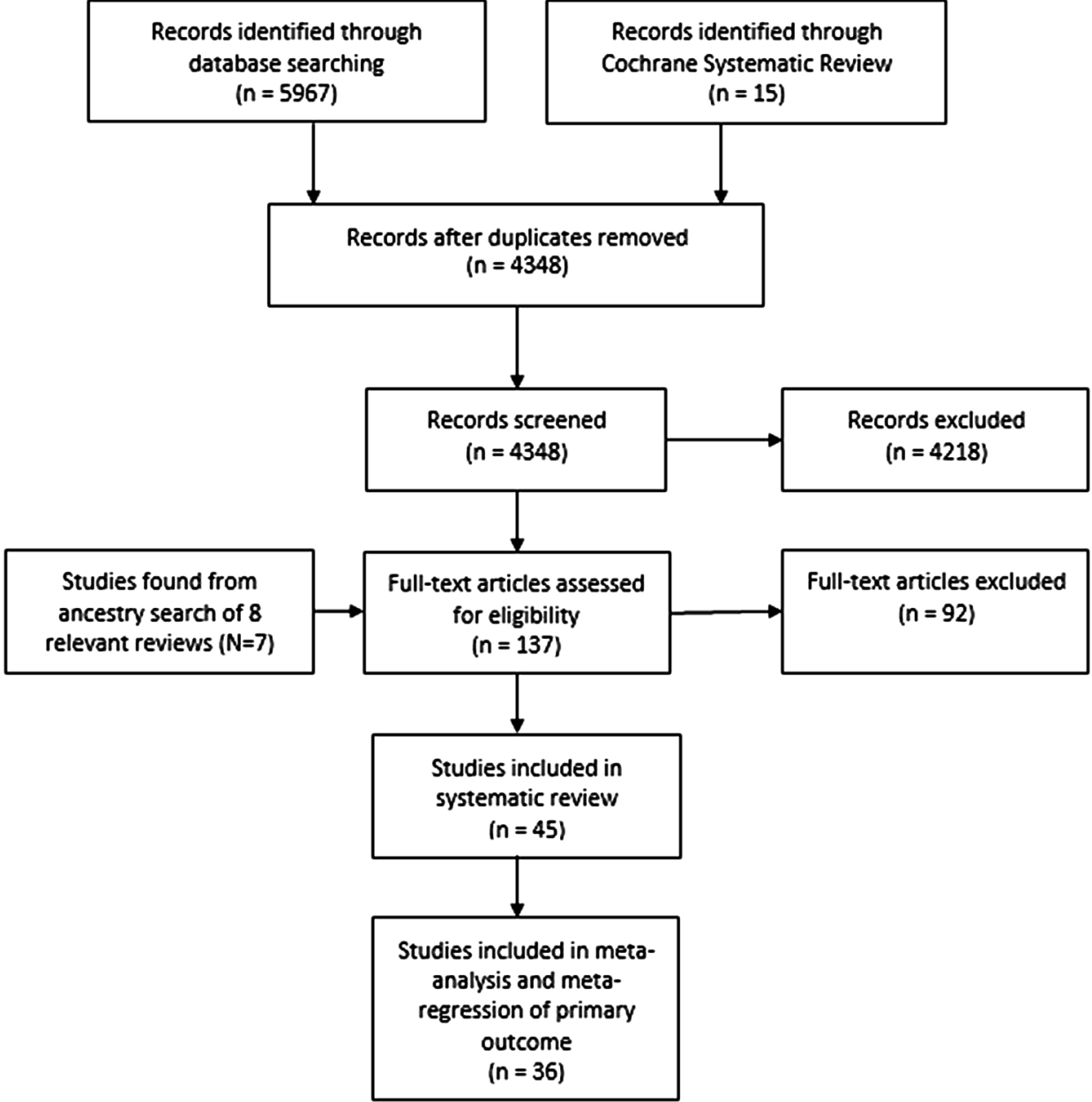

controlled intervention, ${ }^{44} 455061{ }^{74-76}$ one trial ${ }^{64}$ used a waitlist control comparison condition and one trial ${ }^{69}$ used a no-intervention control comparison group (see online supplementary table S3).

\section{Outcomes and measurement}

In 13 trials, self-harm outcomes were measured by participant interview, ${ }^{42} 43 \quad 48 \quad 50-53 \quad 58 \quad 63 \quad 69 \quad 71 \quad 73 \quad 74$ in nine trials via medical records, ${ }^{39} 4647575960626567$ in 13 by

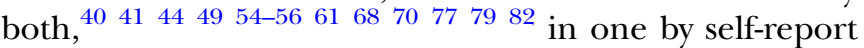
questionnaire, ${ }^{76}$ in two by self-report questionnaire and medical records; ${ }^{72} 78$ and in one via the national surveillance system; ${ }^{81}$ it was unclear in four; ${ }^{38} 656875$ and these outcomes were not collected in two trials ${ }^{45} 80$ (see online supplementary table S3).

\section{Risk of bias within studies}

In 23 of the 45 trials, random sequence generation was not described; in the remaining trials, there was an adequate method. In 22 trials, the method of allocation concealment was not described; in three trials, allocation was clearly not concealed; and in 20 trials, allocation concealment was adequate. Therefore, a high risk of selection bias was likely in over $50 \%$ of trials.

Blinding of participants and the care providers was not possible, so performance bias was likely; however, outcome assessors can be blinded. For 13 trials where the outcome data were obtained by interview, 5 described the rater as blind, 3 as not blind and 5 had no description. In nine trials, the outcome was obtained from medical records; in five of these the rater was blind, in two not blind and it was unclear in two trials. In 13 trials, interview and medical records were used to obtain the outcome; in seven of these the rater was blind, in one not blind and in five it was unclear. In one trial, self-harm data were collected via the National Surveillance system and there was no description of blinding. In four trials, it was not clear how the outcome data were obtained; in one of these trials, the rater was blind. In three trials, self-harm outcomes were collected by self-report questionnaire and therefore cannot be blind. In two studies, self-harm outcomes were not collected. Detection bias was therefore likely in over $50 \%$ of trials.

Nineteen trials were rated as being with a low risk of bias with $<15 \%$ lost to follow-up or missing outcome data. There was a high rate of missing data in 19 trials $(>15 \%)$ and in only 11 was an ITT analysis described; the amount of missing data was unclear in six trials and in only one of these was an ITT analysis described. Therefore, eight trials were rated as being of a high risk of bias, and 17 as unclear so that attrition bias was present or likely in $55.5 \%$ of trials (see table 1 for a 
description of each trial and figure 2 for a summary graph of the risk of bias).

\section{Synthesis of results: meta-analyses}

Primary outcome

The proportion of individuals with any repeat episode of self-harm after an intervention ranged from $0 \%$ to $55 \%$ in the intervention arm, and from $0 \%$ to $71 \%$ in the control arms.

Participants in the psychological or psychosocial interventions (combined) group had 0.84 times the risk of any further episode of self-harm relative to those in the comparator conditions (36 trials; 7354 participants, 95\% CI 0.74 to $0.96 ; \mathrm{p}=0.01 ; \mathrm{I}^{2} 33 \%$ ). This effect translates to an NNT of 33. There was evidence of an effect of CBT (5 trials, RR $0.77 ; 95 \%$ CI 0.64 to 0.93 ) and psychodynamic interpersonal psychotherapy ( 1 trial; RR $0.31 ; 95 \%$ CI 0.12 to 0.78 ) in reducing the rate of repetition compared to comparator conditions. There was no strong evidence that complex interventions with outreach (13 trials, RR $0.90 ; 95 \%$ CI 0.73 to 1.11 ), problem-focused interventions (8 trials, RR $0.96,95 \%$ CI 0.80 to 1.16 ), interventions classed as other-psychological (4 trials, RR 0.91; 95\% CI 0.39 to 2.11 ) or interventions classed as other-psychosocial ( 5 trials, RR 0.86 ; $95 \%$ CI 0.58 to 1.27 ) had an effect on reducing rates of repetition of self-harm (see figure 3).

The direction of effects across trials indicated that some study-specific effect estimates fell within benefit and some fell within harm.

\section{Secondary outcomes}

There was strong evidence that compared with any type of comparator condition, psychological or psychosocial interventions (combined) were associated with reduced severity of suicidal ideation (36 trials, SMD -0.42 ; $95 \%$ CI -0.60 to $\left.-0.25 ; \mathrm{p}<0.00001 ; \mathrm{I}^{2}=64 \%\right)$, depressive symptoms (36 trials, SMD $-0.23 ; 95 \%$ CI -0.36 to -0.10 ; $\mathrm{p}=0.0003 ; \mathrm{I}^{2}=57 \%$ ) and hopelessness (34 trials, mean difference of $-1.47 ; 95 \%$ CI -2.16 to $-0.78 ; \mathrm{p}<0.0001$; $\mathrm{I}^{2}=34 \%$; all trials used the Beck Hopelessness Scale, which has a score range of $0-20$ ).

\section{Additional analyses: sensitivity analyses}

Excluding trials rated as being of a high or unclear risk of bias for allocation concealment and, in a second sensitivity analysis, for outcome rater blinding showed that there was no longer strong evidence for reduction in risk of any self-harm event for concealment (20 trials: RR 0.94; $95 \%$ CI 0.83 to $1.06, \mathrm{I}^{2}=22 \%$ ) and for blinding ( 16 trials: RR $0.84 ; 95 \%$ CI 0.70 to $1.02, \mathrm{I}^{2}=34 \%$ ).

\section{Additional analyses: meta-regression}

Moderating variables: intervention approach and components

Neither the type of intervention, nor the intensity of the intervention nor any of the other binary components of the intervention investigated had any association with the magnitude of the intervention effect $(p=0.365)$ (table 2).

\section{Moderating variables: aspects of methodology}

The sample size of a trial appeared to have a weak association with the magnitude of the effect $(\mathrm{RR}=1.0006$, $\mathrm{p}=0.046$ ) (see table 2) and when the sample size of each intervention was entered in the meta-regression model $(\mathrm{k}=36)$, the $\mathrm{I}^{2}$ value reduced to $22 \%$. There was no significant association between the type of comparator (TAU, TAU+ or an alternative active control intervention) or participant population (ie, on the basis of self-harm, suicide attempt or self-poisoning) and the magnitude of intervention effect.

\section{Assessment of reporting bias}

There was some evidence that there were missing studies (see online supplementary figure $\mathrm{S} 1$ ).

\section{DISCUSSION}

\section{Principal findings}

We included 45 trials of psychological and psychosocial interventions to prevent repeat self-harm and examined the type of intervention and components of interventions that were potential modifiers of overall efficacy. There were three main results from 36 of these trials: (1) there is evidence that any kind of psychological or psychosocial intervention (when combined) aimed at reducing a repeated episode self-harm had a protective effect that represents an important public health impact and is potentially clinically relevant at an individual level compared to any comparator condition; (2) there currently is no strong evidence that the type of intervention modifies overall efficacy; and (3) there was strong evidence of benefits of any kind of psychological or psychosocial interventions on the severity of suicidal ideation, depression symptoms and hopelessness scores. The effects appear to be small, but may be clinically important.

\section{A change in clinical practice is warranted}

Any repeat episode of self-harm is a difficult outcome to influence, in part because it occurs in a minority; most will not repeat after 12 months even without intervention. However, because of the high prevalence of selfharm with a repetition rate of around $16 \%$ at 12 months, ${ }^{1}$ even small beneficial effects will be important at the public health level. The benefit for a clinician considering treatment for an individual patient is not as clear-cut. The relative reduction of $16 \%$ for a repeat selfharm event is small, with an absolute risk reduction of around 3\% (16-13\%). Nonetheless, this reduction translates to an NNT of 33, the same as for a Cochrane review of interventions for the prevention of depression; ${ }^{88}$ and much better than well-accepted interventions, for example, aspirin to prevent a cardiovascular event NNT of $284^{89}$ and antihypertensive medications for those with 
Figure 2 Summary graph of review authors' judgements about each risk of bias item presented as percentages across all included studies.
Random sequence generation (selection bias)

Allocation concealment (selection bias)

Blinding of outcome assessment (detection bias) Incomplete outcome data (attrition bias)

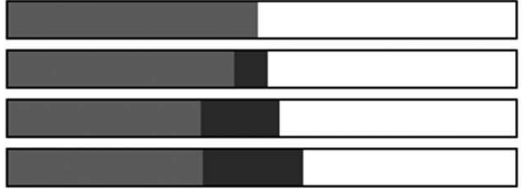

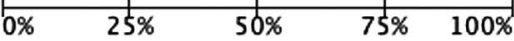

Low risk of bias

High risk of bias

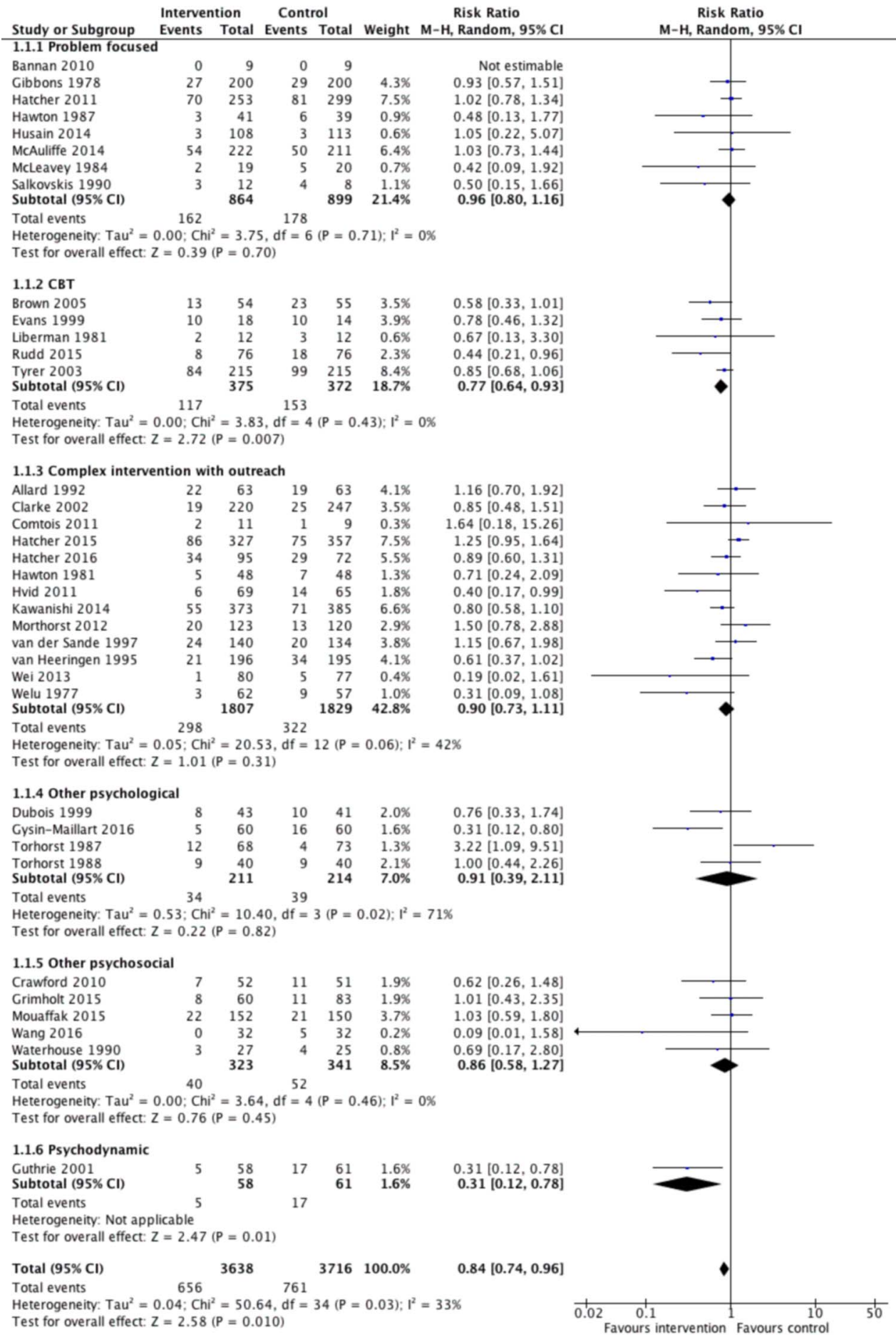

Figure 3 Forest plot of any psychological or psychosocial intervention versus control for self-harm. 
Table 2 Effects of single covariates for meta-regression of all trials of psychological or psychosocial intervention versus comparator

\begin{tabular}{|c|c|c|c|c|c|}
\hline & $\mathbf{k}$ & $\begin{array}{l}\text { Risk ratio } \\
(95 \% \mathrm{Cl})\end{array}$ & p Value & $\begin{array}{l}\text { Adjusted } \\
\mathbf{R}^{2} \%^{*}\end{array}$ & $\mathbf{I}^{2} \%$ (Res) \\
\hline $\begin{array}{l}\text { Any psychological or psychosocial therapy combined } \\
\text { (overall effect) } \\
\text { Explanatory variable } \\
\text { Type of intervention and components } \\
\text { Continuous }\end{array}$ & 36 & $0.84(0.74$ to 0.96$)$ & - & - & 30 \\
\hline Intensity of intervention (min) & 36 & - & 0.10 & 18 & 26 \\
\hline \multicolumn{6}{|l|}{ Binary } \\
\hline Type of intervention & & & & 0 & 28 \\
\hline Problem-focused (reference) & 8 & $0.96(0.80$ to 1.16$)$ & - & & \\
\hline CBT & 5 & $0.77(0.64$ to 0.93$)$ & 0.245 & & \\
\hline Complex intervention with outreach & 13 & $0.90(0.73$ to 1.11$)$ & 0.948 & & \\
\hline Other-psychological & 4 & 0.91 (0.39 to 2.11$)$ & 0.866 & & \\
\hline Other-psychosocial & 5 & 0.86 (0.58 to 1.27$)$ & 0.749 & & \\
\hline Psychodynamic & 1 & $0.31(0.12$ to 0.78$)$ & 0.056 & & \\
\hline \multicolumn{6}{|l|}{ Continuity of care $\dagger$} \\
\hline Same therapist (but as per standard) (reference) & 20 & $0.89(0.26$ to 1.05$)$ & - & 0 & 33 \\
\hline No continuity of clinicians or therapists & 7 & 0.77 (0.55 to 1.07$)$ & 0.482 & & \\
\hline $\begin{array}{l}\text { Continuity (especially between acute and outpatient } \\
\text { services) }\end{array}$ & 6 & 0.83 (0.55 to 1.25$)$ & 0.894 & & \\
\hline Flexibility of the site of delivery & & & & 0 & 25 \\
\hline Clinic only (reference) & 24 & 0.89 (0.78 to 1.02$)$ & - & & \\
\hline Home & 12 & 0.73 (0.54 to 0.98$)$ & 0.352 & & \\
\hline Between-session contactł & & & & 0 & 31 \\
\hline Standard practice only (reference) & 21 & $0.83(0.72$ to 0.95$)$ & - & & \\
\hline Additional contact included & 14 & 0.87 (0.69 to 1.10$)$ & 0.449 & & \\
\hline Enhancement of motivation/compliance & & & & 8 & 28 \\
\hline Standard practice only (reference) & 25 & 0.79 (0.68 to 0.92$)$ & - & & \\
\hline Motivation enhancement included & 11 & 0.95 (0.77 to 1.18$)$ & 0.112 & & \\
\hline Crisis care & & & & 0 & 31 \\
\hline Standard practice only (reference) & 29 & 0.80 (0.69 to 0.93$)$ & - & & \\
\hline $\begin{array}{l}\text { Participants had open access to immediate crisis } \\
\text { care }\end{array}$ & 7 & $1.02(0.79$ to 1.32$)$ & 0.224 & & \\
\hline Treatment setting & & & & 0 & 34 \\
\hline Outpatient care only (reference) & 31 & $0.82(0.70$ to 0.95$)$ & - & & \\
\hline Included inpatient care & 4 & $1.02(0.67$ to 1.55$)$ & 0.913 & & \\
\hline Included day patient care & 1 & 0.85 (0.68 to 106$)$ & 0.610 & & \\
\hline \multicolumn{6}{|l|}{ Aspects of methodology } \\
\hline \multicolumn{6}{|l|}{ Continuous } \\
\hline Sample size & 36 & - & 0.046 & 31 & 23 \\
\hline \multicolumn{6}{|l|}{ Binary } \\
\hline Type of comparison group & & & & 0 & 33 \\
\hline Alternative controlled treatment (reference group) & 5 & $1.01(0.53$ to 1.94$)$ & - & & \\
\hline TAU & 25 & 0.81 (0.68 to 0.96$)$ & 0.453 & & \\
\hline $\mathrm{TAU}_{+}$ & 6 & 0.85 (0.73 to 0.99$)$ & 0.508 & & \\
\hline Population type & & & & 7 & 28 \\
\hline Included on the basis of self harm (reference group) & 11 & $0.96(0.85$ to 1.08$)$ & - & & \\
\hline Included on the basis of SA & 19 & 0.77 (0.60 to 0.98$)$ & 0.221 & & \\
\hline Included on the basis of self-poisoning & 6 & $0.70(0.46$ to 1.05$)$ & 0.225 & & \\
\hline
\end{tabular}

${ }^{*}$ Adjusted $R^{2}$ is the percentage of between-trial variance explained by the included covariates.

†Three trials did not provide enough information about continuity of care and so were not included in the analysis.

fOne trial did not provide enough information about between-session contact and so was not included in the analysis.

CBT, cognitive-behavioural therapy; k, number of comparisons; SA, suicide attempt; TAU, treatment as usual; TAU+, enhanced TAU. 
high blood pressure to prevent a stroke NNT of $169 .{ }^{90}$ From the clinician's viewpoint, there were also benefits on suicidal ideation, depression and hopelessness. Using Cohen's rule, these differences are small but may not be trivial, particularly because severity of suicidal ideation is associated with the risk of suicide attempt. ${ }^{91} 92$

It would be worthwhile for clinicians treating patients who have presented to hospital with self-harm to consider a psychological or psychosocial intervention; with the best choices being CBT or, based on one trial to date, psychodynamic interpersonal therapy. This is consistent with the NICE guidelines for after-care recommending that clinicians 'consider offering 3 to 12 sessions of a psychological intervention that is specifically structured for people who self-harm'. ${ }^{27}$

\section{Potential cost savings}

There have been no cost-effectiveness or cost-utility analyses for psychosocial interventions aimed at reducing repetition of self-harm; and now that overall clinical benefit has been demonstrated to be possible, we expect that these analyses should be incorporated into future well-designed studies. There have also been only infrequent analyses of improved opportunity costs to the health system, based on reduced admission rates or length of stay for self-harm interventions. ${ }^{93}$ However, before any intervention can be considered to be scaled up for widespread availability, the prospect of direct and substantial cost savings to the health system needs to be demonstrated. To illustrate this point, we have made some speculative calculations about possible direct cost savings.

For England, the annual number of hospital-treated self-harm events is $\sim 220000,{ }^{94}$ with a third (73 333) likely to be repeat events; so providing intervention could potentially avoid 2200 events (by reducing the risk of repetition in this group from $16 \%$ to $13 \%$ ). Assuming $90 \%$ of these require ambulance transport (cost $£ 246^{95}$ per trip; savings $£ 487080), 100 \%$ attend emergency department ( $£ 110$ per attendance ${ }^{95}$ savings $£ 242000$ ) and $60 \%$ are admitted (£204-£4231per admission; ${ }^{95}$ midpoint cost of £2217; savings £2 926440 ), this is a potential savings of around $£ 3655520$ per year. For Australia, based on sentinel service monitoring, ${ }^{96}$ the scaled up annual national number of hospital-treated self-poisoning events is 79920 ; a third are estimated repeat events, with around 800 hospital presentations potentially avoided. Hospital treatment costs are $\$ \mathrm{~A} 3015^{97}$ (without complication) or $\$ \mathrm{~A} 8534^{97}$ (with complications); at a ratio of $6: 1,{ }^{98}$ this is a potential cost savings of \$A3 041166 per year.

\section{Strengths and limitations}

This review has significantly updated the evidence base by identifying 45 relevant RCTs undertaken in self-harm populations; this is the largest number of psychological and psychosocial trials identified in a systematic review. We have not included brief contact interventions (summarised elsewhere ${ }^{16}$ ), nor investigated the effectiveness of interventions for specific targeted subpopulations, such as those with BPD or psychosis, therefore no trials of DBT, mentalisation or schema-focused therapy are included. It should also be noted that the majority of trials were undertaken in populations who presented to a general hospital and many people who engage in self-harm do not present in this way.

Our review adopted robust systematic review methodology, including analysis of meaningful secondary outcomes, sensitivity analysis to assess the impact of risk of bias on the results and analyses that examined whether the type of intervention modified the intervention effect. Nevertheless, the results of the meta-analysis and meta-regression in this review should be treated with some caution given that the risk of bias in various domains was rated as high. When poorer quality trials (those with a high risk of bias with regard to allocation concealment, and separately for outcome assessor blinding) were excluded from the analysis in sensitivity analysis, there was no strong evidence of the effect of the interventions on repetition of self-harm, although it may be that the analysis was then limited in terms of power. We noted significant limitations in the reporting of the nature of psychological and psychosocial interventions delivered and point to the template for intervention description and replication (TIDier) guidelines for reporting of interventions. ${ }^{99}$ There were few trials in some categories of intervention type, limiting the power to investigate whether the type of intervention modifies the overall intervention effect. This requires further investigation. Given the relatively small number of trials, we did not have the data to enter all the multiple confounders into the same analysis or test interactions. It should be noted that there is diversity in terms of the populations included, for example, social context, the types of interventions (we have focused our attention on a number of confounders with regard to this diversity) and methodological factors, for example, Zelen versus conventional randomisation. Therefore, it is possible that the variation in intervention effects can be explained by other, or a combination of variables. In terms of the meta-regression, the results are observational in nature and cannot infer causality (ie, the effect seen may be due to a third factor); as such they are considered to be hypothesis generating rather than providing robust conclusions. ${ }^{100}$

There is little information available about treatment costs or cost-effectiveness for any after-care intervention. We have not investigated other important self-harm outcomes, such as time to first repeat self-harm episode or number of repetition events; and few if any studies report adverse events, which would also assist the clinician in decision-making about treatment options.

\section{Implications and future research}

The trials in this meta-regression included unselected populations of participants who had recently engaged in 
self-harm where the most common reasons for hospital presentation are interpersonal and social problems. ${ }^{101}$ Therefore, psychological and psychosocial therapies focusing on proximal interpersonal issues are plausible, and the single trial of four sessions of psychodynamic-influenced interpersonal therapy ${ }^{55}$ fits this approach. This trial has not been replicated and this type of therapy warrants a future large-scale trial. Hospital-treated self-harm populations are heterogeneous in terms of psychiatric diagnosis and life problems. The way forward might be to develop targeted interventions for clinically important subpopulations classified by age, gender, life problem, substance misuse or other criteria in line with the needs-based approach to assessment and after-care as recommended by the NICE guidelines. ${ }^{102}$ Future interventions to be developed and evaluated might contain particular elements: CBT based, with an interpersonal focus targeted on the psychosocial precipitants to the self-harm event.

\section{CONCLUSIONS}

Our study is consistent with the updated Cochrane review, ${ }^{14}$ which in contrast to the original version ${ }^{5}$ showed no support for problem-focused (predominantly problem-solving therapy) interventions but a significant effect of CBT. The updated Cochrane review ${ }^{14}$ and other reviews ${ }^{18} 1996$ have shown DBT to be effective for patients with BPD; ${ }^{18} 1996$ similarly brief contact interventions are promising for unselected self-harm patients. ${ }^{16}$ Our study has shown that psychological or psychosocial interventions are effective overall, with CBT and psychodynamic interpersonal therapy currently the most promising for implementation.

\section{Author affiliations}

${ }^{1}$ Orygen, The National Centre of Excellence in Youth Mental Health, Melbourne, Victoria, Australia

${ }^{2}$ Centre for Youth Mental Health, The University of Melbourne, Melbourne, Victoria, Australia

${ }^{3}$ Melbourne School of Population and Global Health, The University of Melbourne, Melbourne, Victoria, Australia

${ }^{4}$ Centre for Translational Neuroscience and Mental Health, The University of Newcastle, Newcastle, New South Wales, Australia

Acknowledgements The study was conducted at Orygen, the National Centre of Excellence in Youth Mental Health and the Centre for Youth Mental Health at the University of Melbourne.

Contributors All authors have contributed substantially to the systematic review, analyses included in it and in the write-up of the manuscript. GC and SEH conceived of the study and developed the protocol; SEH and JR selected studies for inclusion and extracted data; SEH, GC and MJS did the analyses; SEH prepared the manuscript with input from all authors.

Funding This research received no specific grant from any funding agency in the public, commercial or not-for-profit sectors.

Competing interests GC chaired the Royal Australian and New Zealand College of Psychiatrists Clinical Practice Guidelines for Deliberate Self-harm, but the views in this paper are the author's own and not those of the RANZCP. SEH and JR are authors for the Royal Australian and New Zealand College of Psychiatrists Clinical Practice Guidelines for Deliberate Self-harm but the views in this paper are the author's own and not those of the RANZCP. All authors have completed the Unified Competing Interest form at http://www.icmje.org/coi_disclosure.pdf (available on request from the corresponding author) and declare that SEH, JR, MJS and GC do not have any support from any organisation for the submitted work; SEH, JR, MJS and GC have no financial relationships with any organisations that might have an interest in the submitted work in the previous 3 years; neither do their spouses, partners or children have any financial relationships that may be relevant to the submitted work; and SEH, JR, MJS and GC do not have any other relationships or activities that could appear to have influenced the submitted work. All authors have seen and approved the manuscript being submitted. They warrant that the article is the authors' original work, has not received prior publication and is not under consideration for publication elsewhere.

Provenance and peer review Not commissioned; externally peer reviewed.

Data sharing statement No additional data are available.

Open Access This is an Open Access article distributed in accordance with the Creative Commons Attribution Non Commercial (CC BY-NC 4.0) license, which permits others to distribute, remix, adapt, build upon this work noncommercially, and license their derivative works on different terms, provided the original work is properly cited and the use is non-commercial. See: http:// creativecommons.org/licenses/by-nc/4.0/

\section{REFERENCES}

1. Owens D, Horrocks J, House A. Fatal and non-fatal repetition of self-harm. Systematic review. Br J Psychiatry 2002;181:193-9.

2. Carroll R, Metcalfe C, Gunnell D. Hospital presenting self-harm and risk of fatal and non-fatal repetition: systematic review and meta-analysis. PLOS ONE 2014;9:e89944.

3. Robinson J, Hetrick SE, Martin C. Preventing suicide in young people: systematic review. Aust N Z J Psychiatry 2011;45:3-26.

4. Burns J, Dudley M, Hazell P, et al. Clinical management of deliberate self-harm in young people: the need for evidence-based approaches to reduce repetition. Aust N Z J Psychiatry 2005;39:121-8.

5. Hawton KKE, Townsend E, Arensman E, et al. Psychosocial and pharmacological treatments for deliberate self-harm. Cochrane Database Syst Rev 1999;CD001764.

6. Crawford MJ, Thomas O, Khan N, et al. Psychosocial interventions following self-harm: systematic review of their efficacy in preventing suicide. Br J Psychiatry 2007:190:11-17.

7. Kerkhof AJFM, Mishara BL. Promising practices, future prospects and research agenda. In: Mishara BL, Kerkhof AJFM, eds. Suicide prevention and new technologies: evidence based practice. New York, USA: Palgrave MacMillan, 2013:181-94.

8. Brown $\mathrm{CH}$, Wyman PA, Guo J, et al. Dynamic wait-listed designs for randomized trials: new designs for prevention of youth suicide. Clin Trials 2006;3:259-71.

9. Arensman E, Townsend E, Hawton $\mathrm{K}$, et al. Psychosocial and pharmacological treatment of patients following deliberate self-harm: the methodological issues involved in evaluating effectiveness. Suicide Life Threat Behav 2001;21:169-80.

10. Hawton K, Townsend E, Arensman E, et al. Psychosocial and pharmacological treatments for deliberate self harm. Issue 3 . The Cochrane Collaboration, 2003

11. De Leo D, Burgis S, Bertolote J, et al. Definitions of suicidal behavior: lessons learned from the WHO/EURO multicentre study. Crisis 2006;27:4-15

12. Silverman MM, Berman AL, Sanddal ND, et al. Rebuilding the tower of Babel: a revised nomenclature for the study of suicide and suicidal behaviors. Part 1: background, rationale, and methodology. Suicide Life Threat Behav 2007;37:248-63.

13. Hawton K, Townsend E, Arensman E, et al. Psychosocial and pharmacological treatments for deliberate self-harm (review). Cochrane Database Syst Rev 1999:CD001764.

14. Hawton K, Witt KG, Taylor Salisbury TL, et al. Pharmacological interventions for self-harm in adults. Cochrane Database Syst Rev 2015;CD011777.

15. Hawton K, Witt KG, Taylor Salisbury TL, et al. Psychosocial interventions for self-harm in adults. Cochrane Database Syst Rev 2016:CD012189.

16. Milner AJ, Carter G, Pirkis J, et al. Letters, green cards, telephone calls, and postcards: a systematic and meta-analytic review of brief contact interventions for reducing self-harm, suicide attempts, and suicide. Br J Psychiatry 2015;206:184-90.

17. National Health and Medical Research Council (NHMRC). Clinical practice guideline for the management of borderline personality 
disorder. Canberra, Australia: National Health and Medical Research Council, 2012.

18. Kliem S, Kröger C, Kosfelder J. Dialectical behavior therapy for borderline personality disorder: a meta-analysis using mixed-effects modeling. J Consult Clin Psychol 2010;78:936-51.

19. Panos PT, Jackson JW, Hasan O, et al. Meta-analysis and systematic review assessing the efficacy of dialectical behavior therapy (DBT). Res Soc Work Pract 2013;24:213-23.

20. Tarrier N, Taylor K, Gooding P. Cognitive-behavioral interventions to reduce suicide behavior: a systematic review and meta-analysis. Behav Modif 2008;32:77-108

21. Cuijpers $P$, de Beurs D, van Spijker B, et al. The effects of psychotherapy for adult depression on suicidality and hopelessness: a systematic review and meta-analysis. $J$ Affect Disord 2013;144:183-90.

22. O'Connor E, Gaynes B, Burda BU, et al. Screening for suicide risk in primary care: a systematic evidence review for the US Preventive Services Task Force. Evidence Synthesis No. 103. AHRQ Publication No. 13-05188-EF-1. Rockville (MD): Agency for Healthcare Research and Quality, 2013.

23. Daigle MS, Pouliot L, Chagnon F, et al. Suicide attempts: prevention of repetition. Can J Psychiatry 2011;56:621-9.

24. Brown GK, Green KL. A review of evidence-based follow-up care for suicide prevention: where do we go from here? Am J Prev Med 2014;47:S209-15.

25. Inagaki M, Kawashima Y, Kawanishi C, et al. Interventions to prevent repeat suicidal behavior in patients admitted to an emergency department for a suicide attempt: a meta-analysis. $J$ Affect Disord 2015;175:66-78.

26. Comtois KA, Linehan MM. Psychosocial treatments of suicidal behaviors: a practice-friendly review. J Clin Psychol 2006;62:161-70

27. National Institute for Health and Clinical Excellence (NICE). Self-harm: longer-term management. NICE clinical guideline133 guidance.nice.org.uk/cg133, 2011 (issued November 2011).

28. Higgins JPT, Green S. Cochrane handbook for systematic reviews of interventions version 5.1.0 [updated March 2011]. The Cochrane Collaboration, 2011. http://www.cochrane-handbook.org

29. Coventry PA, Hudson JL, Kontopantelis E, et al. Characteristics of effective collaborative care for treatment of depression: a systematic review and meta-regression of 74 randomised controlled trials. PLOS ONE 2014;9:e108114.

30. Cape J, Whittington C, Buszewicz M, et al. Brief psychological therapies for anxiety and depression in primary care: meta-analysis and meta-regression. BMC Med 2010;8:38

31. Moher D, Liberati A, Tetzlaff J, et al. Preferred reporting items for systematic reviews and meta-analyses: the PRISMA statement. Int J Surg 2010;8:336-41.

32. Chalmers TC, Celano P, Sacks HS, et al. Bias in treatment assignment in controlled clinical trials. $N$ Engl J Med 1983;309:1358-62.

33. Nock MK, Borges G, Bromet EJ, et al. Suicide and suicidal behavior. Epidemiol Rev 2008;30:133-54.

34. Hawton K, Rodham K, Evans E, et al. Deliberate self harm in adolescents: self report survey in schools in England. BMJ 2002;325:1207-11.

35. Joiner T, Brown J, Wingate L. The psychology and neurobiology of suicidal behavior. Annu Rev Psychol 2005;56:287-314.

36. Hetrick SE, Parker AG, Robinson J, et al. Predicting suicidal risk in a cohort of depressed children and adolescents. Crisis 2012;33:13-20.

37. Higgins JP, Altman DG, Gotzsche PC, et al. The Cochrane Collaboration's tool for assessing risk of bias in randomised trials. BMJ 2011;343:d5928.

38. Bannan N. Group-based problem-solving therapy in self-poisoning females: a pilot study. Counsel Psychother Res 2010;10:201-13.

39. Gibbons JS, Butler J, Urwin P, et al. Evaluation of a social work service for self-poisoning patients. Br J Psychiatry 1978;133:111-18.

40. Hatcher S, Sharon C, Parag V, et al. Problem-solving therapy for people who present to hospital with self-harm: Zelen randomised controlled trial. Br J Psychiatry 2011;199:310-16.

41. Hawton K, McKeown S, Day A. Evaluation of outpatient counselling compared with general practitioner care following overdoses. Psychol Med 1987;17:751-61.

42. Husain N, Afsar S, Ara J, et al. Brief psychological intervention after self-harm: randomised controlled trial from Pakistan. Br J Psychiatry 2014;204:462-70.

43. McAuliffe C, McLeavey BC, Fitzgerald T, et al. Group problem-solving skills training for self-harm: randomised controlled trial. Br J Psychiatry 2014;204:383-90.
44. McLeavey BC, Daly RJ, Ludgate JW, et al. Interpersonal problem-solving skills training in the treatment of self poisoning patients. Suicide Life Threat Behav 1994;24:382-94.

45. Patsiokas AT, Clum GA. Effects of psychotherapeutic strategies in the treatment of suicide attempters. Psychotherapy 1985;22:281-90.

46. Stewart CD, Quinn A, Plever S, et al. Comparing cognitive behavio therapy, problem solving therapy, and treatment as usual in a high risk population. Suicide Life Threat Behav 2009;39:538-47.

47. Salkovskis $\mathrm{P}$, Atha $\mathrm{C}$, Storer D. Cognitive-behavioural problem solving in the treatment of patients who repeatedly attempt suicide. A controlled trial. Br J Psychiatry 1990;157:871-6.

48. Brown GK, Have TT, Henriques GR, et al. Cognitive therapy for the prevention of suicide attempts: a randomized controlled trial. JAMA 2005;294:563-70.

49. Evans K, Tyrer P, Catalan J, et al. Manual-assisted cognitive behaviour therapy (MACT): a randomized controlled trial of a brief intervention with a bibliotherapy in the treatment of recurrent deliberate self harm. Psychol Med 1999;29:19-25.

50. Liberman RP, Eckman T. Behavior therapy vs insight oriented therapy for repeated suicide attempters. Arch Gen Psychiatry 1981;38:1126-30.

51. Morley KC, Sitharthan G, Haber PS, et al. The efficacy of an opportunistic cognitive behavioral intervention package (OCB) on substance use and comorbid suicide risk: a multisite randomized controlled trial. J Consult Clin Psychol 2014;82:130-40.

52. Rudd M, Bryan CJ, Wertenberger EG, et al. Brief cognitive-behavioral therapy effects on post-treatment suicide attempts in a military sample: results of a randomized clinical trial with 2-year follow-up. Am J Psychiatry 2015;172:441-9.

53. Slee N, Garnefski N, van der Leeden R, et al. Cognitive-behavioural intervention for self-harm: randomised controlled trial. Br J Psychiatry 2008;192:202-11.

54. Tyrer $\mathrm{P}$, Thompson S, Schmidt U, et al. Randomized controlled trial of brief cognitive behaviour therapy versus treatment as usual in recurrent deliberate self-harm: the POPMACT study. Psychol Med 2003;33:969-76.

55. Guthrie E, Kapur N, Mackway-Jones K, et al. Randomised controlled trial of brief psychological intervention after deliberate self poisoning. BMJ 2001;323:135-8.

56. Allard R, Marshall M, Plante MC. Intensive follow-up does not decrease the risk of repeat suicide attempts. Suicide Life Threat Behav 1992;22:303-14.

57. Clarke T, Baker P, Watts CJ, et al. Self-harm in adults: a randomised controlled trial of nurse-led case management versus routine care only. $J$ Ment Health 2002;11:167-76.

58. Comtois KA, Jobes DA, O'Connor SS, et al. Collaborative assessment and management of suicidality (CAMS): feasibility trial for next-day appointment services. Depress Anxiety 2011;28:963-72.

59. Hatcher S, Sharon C, House A, et al. The ACCESS study: Zelen randomised controlled trial of a package of care for people presenting to hospital after self-harm. Br J Psychiatry 2015;206:229-36.

60. Hatcher S, Coupe N, Wikiriwhi K, et al. Te ira tangata: a Zelen randomised controlled trial of a culturally informed treatment compared to treatment as usual in Maori who present to hospital after self-harm. Soc Psychiatry Psychiatr Epidemiol 2016:51:885-94

61. Hawton K, Bancroft J, Catalan J, et al. Domiciliary and outpatient treatment of self-poisoning patients by medical and non-medical staff. Psychol Med 1981;11:169-77.

62. Hvid M, Vangborg K, Sørensen HJ, et al. Preventing repetition of attempted suicide-II. The Amager project, a randomized controlled trial. Nord J Psychiatry 2011;65:292-8.

63. Kawanishi C, Aruga T, Ishizuka N, et al. Assertive case management versus enhanced usual care for people with mental health problems who had attempted suicide and were admitted to hospital emergency departments in Japan (ACTION-J): a multicentre, randomised controlled trial. Lancet Psychiatry 2014;1:193-201.

64. Marasinghe RB, Edirippulige S, Kavanagh D, et al. Effect of mobile phone-based psychotherapy in suicide prevention: a randomized controlled trial in Sri Lanka. J Telemed Telecare 2012;18:151-5.

65. Morthorst B, Krogh J, Erlangsen A, et al. Effect of assertive outreach after suicide attempt in the AID (assertive intervention for deliberate self harm) trial: randomised controlled trial. $B M J$ 2012;345:1-10.

66. Litman RE, Wold Cl. Beyond crisis intervention. In: Shneidman ES ed. Suicidology: contemporary developments. New York: Grune \& Stratton, 1976:528-46. 
67. van der Sande R, van Rooijen E, Buskens E, et al. Intensive in-patient and community intervention versus routine care after attempted suicide: a randomised controlled intervention. Br J Psychiatry 1997;171:35-41.

68. van Heeringen $\mathrm{C}$, Jannes $\mathrm{S}$, Buylaert $\mathrm{W}$, et al. The management of non-compliance with referral to out-patient after-care among attempted suicide patients: a controlled intervention study. Psychol Med 1995;25:963-70.

69. Wei S, Liu L, Bi B, et al. An intervention and follow-up study following a suicide attempt in the emergency departments of four general hospitals in Shenyang, China. Crisis 2013;34:107-15.

70. Welu TC. A follow-up program for suicide attempters: evaluation of effectiveness. Suicide Life Threat Behav 1977;7:17-30.

71. Dubois L, Walter M, Bleton L, et al. Evaluation comarative et prospective d'un protocole de prise en charge specifique de jeunes suicidants: analyse du diagnostic psychiatrique initial, de l'observance therapeutique et du taux de recidive a un an (resultats prelininaires). Ann Med Psychol 1999;157:557-61.

72. Gysin-Maillart A, Schwab S, Soravia L, et al. A novel brief therapy for patients who attempt suicide: a 24-months follow-up randomized controlled study of the Attempted Suicide Short Intervention Program (ASSIP). PLoS Med 2016;13:e1001968.

73. Tapolaa V, Lappalainen R, Wahlström J. Brief intervention for deliberate self harm: an exploratory study. Suicidology Online 2010;1:95-108.

74. Torhorst A, Moller HJ, B F, et al. The psychiatric management of parasuicide patients: a controlled clinical study comparing different strategies of outpatient treatment. Crisis 1987;8:53-61.

75. Torhorst A, Möller HJ, Kurz A, et al. Comparing a 3-month and a 12-month-outpatient aftercare program for parasuicide repeaters. In: Moller HJ, Schmidtke A, Welz R, eds. Current issues of suicidology. Berlin: Springer-Verlag, 1988:419-24.

76. Armitage CJ, Rahim WA, Rowe R, et al. An exploratory randomised trial of a simple, brief psychological intervention to reduce subsequent suicidal ideation and behaviour in patients admitted to hospital for self-harm. Br J Psychiatry 2016;208:470-6.

77. Crawford MJ, Csipke E, Brown A, et al. The effect of referral for brief intervention for alcohol misuse on repetition of deliberate self-harm: an exploratory randomized controlled trial. Psychol Med 2010;40:1821-8

78. Grimholt TK, Jacobsen D, Haavet OR, et al. Effect of systematic follow-up by general practitioners after deliberate self-poisoning: a randomised controlled trial. PLoS ONE 2015;10:e0143934.

79. Mouaffak F, Marchand A, Castaigne $\mathrm{E}$, et al. OSTA program: a French follow up intervention program for suicide prevention. Psychiatry Res 2015;230:913-18.

80. O'Connor SS, Comtois KA, Wang J, et al. The development and implementation of a brief intervention for medically admitted suicide attempt survivors. Gen Hosp Psychiatry 2015;37:427-33.

81. Wang YC, Hsieh LY, Wang MY, et al. Coping card usage can further reduce suicide reattempt in suicide attempter case management within 3-month intervention. Suicide Life Threat Behav 2016;46:106-20.

82. Waterhouse J, Platt S. General hospital admission in the management of parasuicide: a randomised controlled trial. Br J Psychiatry 1990;156:236-42.

83. Schulz KF, Chalmers I, Hayes RJ, et al. Empirical evidence of bias: dimensions of methodological quality associated with estimates of treatment effects in controlled trials. JAMA 1995;273:408-12.
84. Weinberg I, Ronningstam E, Goldblatt MJ, et al. Strategies in treatment of suicidality: identification of common and treatment-specific interventions in empirically supported treatment manuals. J Clin Psychiatry 2010;71:699-706.

85. Hepp U, Wittmann L, Schnyder U, et al. Psychological and psychosocial interventions after attempted suicide: an overview of treatment studies. Crisis 2004;25:108-17.

86. Goldney RD. Suicide prevention: a pragmatic review of recent studies. Crisis 2005;26:128-40.

87. Grimholt TK, Jacobsen D, Haavet OR, et al. Structured follow-up by general practitioners after deliberate self-poisoning: a randomised controlled trial. BMC Psychiatry 2015;15:245.

88. Hetrick SE, Cox GR, Witt KG, et al. Cognitive behavioural therapy (CBT), third-wave CBT and interpersonal therapy (IPT) based interventions for preventing depression in children and adolescents. Cochrane Database Syst Rev 2016;8:CD003380.

89. Xie M, Shan Z, Zhang Y, et al. Aspirin for primary prevention of cardiovascular events: meta-analysis of randomized controlled trials and subgroup analysis by sex and diabetes status. PLOS ONE 2014;9:e90286.

90. Sipahi I, Swaminathan A, Natesan V, et al. Effect of antihypertensive therapy on incident stroke in cohorts with prehypertensive blood pressure levels: a meta-analysis of randomized controlled trials. Stroke 2012;43:432-40.

91. Witte TK, Fitzpatrick KK, Warren KL, et al. Naturalistic evaluation of suicidal ideation: variability and relation to attempt status. Behav Res Ther 2006;44:1029-40.

92. Witte TK, Fitzpatrick KK, Joiner TE, et al. Variability in suicidal ideation: a better predictor of suicide attempts than intensity or duration of ideation? J Affect Disord 2005;88:131-6.

93. Carter GL, Clover K, Whyte IM, et al. Postcards from the EDge: 5-year outcomes of a randomised controlled trial for hospital-treated self-poisoning. Br J Psychiatry 2013;202:372-80.

94. Hawton K, Bergen H, Casey D, et al. Self-harm in England: a tale of three cities. Soc Psychiatry Psychiatr Epidemiol 2007;42:513-21.

95. (NICE) NIfHaCE. Self-harm: longer-term management: costing report: implementing NICE GUidance. Manchester: NICE, 2011.

96. Hiles S, Bergen H, Hawton K, et al. General hospital-treated self-poisoning in England and Australia: comparison of presentation rates, clinical characteristics and aftercare based on sentinel unit data. J Psychosom Res 2015;78:356-62.

97. Independent Hospital Pricing Authority. National hospital cost data collection Australian Public Hospitals Cost Report 2012-2013, Round 17. Sydney: Commonwealth of Australia, 2015.

98. Whyte IM, Dawson AH, Buckley NA, et al. Health care. A model for the management of self-poisoning. Med J Aust 1997;167:142-6.

99. Hoffmann TC, Erueti C, Glasziou PP. Poor description of non-pharmacological interventions: analysis of consecutive sample of randomised trials. BMJ 2013;347:10

100. Thompson SG, Higgins J. How should meta-regression analyses be undertaken and interpreted? Stat Med 2002;21:1559-73.

101. Haw C, Hawton K. Life problems and deliberate self-harm: associations with gender, age, suicidal intent and psychiatric and personality disorder. J Affect Disord 2008;109:139-48.

102. National Institute for Health and Clinical Excellence (NICE). The short-term physical and psychological management and secondary prevention of self-harm in primary and secondary care. NICE clinical guideline 16, 2004 (issued July 2004). http://www.nice.org uk/cg16 